\title{
Differences in activity-related behaviour among patients with chronic low back pain
}

Citation for published version (APA):

Huijnen, I. P. J., Verbunt, J. A., Peters, M. L., Smeets, R. J. E. M., Kindermans, H. P. J., Roelofs, J., Goossens, M., \& Seelen, H. A. M. (2011). Differences in activity-related behaviour among patients with chronic low back pain. European Journal of Pain, 15(7), 748-755.

https://doi.org/10.1016/j.ejpain.2010.11.015

Document status and date:

Published: 01/08/2011

DOI:

10.1016/j.ejpain.2010.11.015

Document Version:

Publisher's PDF, also known as Version of record

Document license:

Taverne

Please check the document version of this publication:

- A submitted manuscript is the version of the article upon submission and before peer-review. There can be important differences between the submitted version and the official published version of record.

People interested in the research are advised to contact the author for the final version of the publication, or visit the DOI to the publisher's website.

- The final author version and the galley proof are versions of the publication after peer review.

- The final published version features the final layout of the paper including the volume, issue and page numbers.

Link to publication

\footnotetext{
General rights rights.

- You may freely distribute the URL identifying the publication in the public portal. please follow below link for the End User Agreement:

www.umlib.nl/taverne-license

Take down policy

If you believe that this document breaches copyright please contact us at:

repository@maastrichtuniversity.nl

providing details and we will investigate your claim.
}

Copyright and moral rights for the publications made accessible in the public portal are retained by the authors and/or other copyright owners and it is a condition of accessing publications that users recognise and abide by the legal requirements associated with these

- Users may download and print one copy of any publication from the public portal for the purpose of private study or research.

- You may not further distribute the material or use it for any profit-making activity or commercial gain

If the publication is distributed under the terms of Article $25 \mathrm{fa}$ of the Dutch Copyright Act, indicated by the "Taverne" license above, 


\title{
Differences in activity-related behaviour among patients with chronic low back pain
}

\author{
Ivan P.J. Huijnen ${ }^{\mathrm{a}, *}$, Jeanine A. Verbunt ${ }^{\mathrm{a}, \mathrm{b}}$, Madelon L. Peters ${ }^{\mathrm{c}}$, Rob J.E.M. Smeets ${ }^{\mathrm{a}, \mathrm{b}}$, Hanne P.J. Kindermans ${ }^{\mathrm{c}}$, \\ Jeffrey Roelofs ${ }^{c}$, Marielle Goossens ${ }^{c}$, Henk A.M. Seelen ${ }^{\mathrm{a}, \mathrm{b}}$
}

${ }^{a}$ Department of Rehabilitation Medicine, Research School CAPHRI, Maastricht University, P.O. Box 616, 6200 MD Maastricht, The Netherlands

${ }^{\mathrm{b}}$ Adelante, Centre of Expertise in Rehabilitation and Audiology, P.O. Box 88, 6430 AB Hoensbroek, The Netherlands

${ }^{\mathrm{c}}$ Department of Clinical Psychological Science, Maastricht University, P.O. Box 616, 6200 MD Maastricht, The Netherlands

\section{A R T I C L E I N F O}

\section{Article history:}

Received 24 June 2010

Received in revised form 2 November 2010

Accepted 29 November 2010

Available online 30 December 2010

\section{Keywords:}

Chronic low back pain

Activity-related behaviour

Accelerometry

\begin{abstract}
A B S T R A C T
The aim of the present study was to compare the subjectively reported and objectively assessed activityrelated characteristics of patients with Chronic Low Back Pain (CLBP) who were classified according to their scores on the Patterns of Activity Measure-Pain (POAM-P) into avoiders, persisters, mixed performers (i.e. high scores on both avoidance and persistence behaviour) or functional performers (i.e. low scores on avoidance and persistence behaviour).

Patients carried an electronic diary during 14 days to assess the self-reported activity and pain intensity levels in daily life. An accelerometer was used to objectively assess their activity level during the same time period.

Results were available for 79 patients. Avoiders, persisters and mixed performers showed a higher level of self-reported disability than functional performers. Avoiders were characterized by a low level of selfreported habitual activities and persisters by long objectively measured daily uptime. The objectively assessed level of physical activity did not differ between the four groups. A further analysis tested the association between pain intensity levels and self-reported and objectively assessed daily life activity levels in avoiders and persisters. In persisters, a higher level of self-reported activities in daily life was related to increased pain. The objectively assessed activity level was not associated with pain intensity.

(c) 2010 European Federation of International Association for the Study of Pain Chapters. Published by Elsevier Ltd. All rights reserved.
\end{abstract}

\section{Introduction}

One of the most prominent models to explain disability in patients with chronic low back pain (CLBP) is the cognitive behavioural fear-avoidance model (Vlaeyen and Linton, 2000). This model proposes that catastrophic interpretations about pain and elevated pain-related fear levels might lead to avoidance behaviour. In the long run this may lead to a chronic pain problem, characterized by disability in daily life functioning, depression, and a lower daily life activity level. Although numerous studies have confirmed the different steps in this model, no consistent evidence exists for the assumed lower activity level of patients with CLBP (Verbunt et al., 2001; Leeuw et al., 2007). In acute low back pain higher levels of pain-related fear and longer periods of bed rest were found. However in CLBP this finding could not be confirmed (Verbunt et al., 2008). Furthermore, several studies showed that the mean activity level of patients with CLBP did not differ from that of healthy individuals (Verbunt et al., 2001; Bousema et al., 2007; van Weering et al., 2009). It seems therefore that not all

\footnotetext{
* Corresponding author. Tel.: +31 455282381; fax: +31 455282348.

E-mail address: ivan.huijnen@maastrichtuniversity.nl (I.P.J. Huijnen).
}

patients with CLBP who are disabled avoid activities (Bousema et al., 2007).

The avoidance-endurance model postulates that there are two different routes to increased pain-related disability. According to this model chronic pain patients can display two alternative activity-related strategies: an avoidant strategy which is characterized by low activity levels, or a strategy that is characterized by persistence in activities (Hasenbring and Verbunt, 2010; Hasenbring et al., 2001). Whereas avoiders will try to escape from activities for which they expect an increase of pain or injury, persisters tend to continue their activities despite pain, until completion is reached. However, after completion of the activity, pain might increase, which, in turn, force persisters to take rest until the pain subsides (Harding and Williams, 1998; Birkholtz et al., 2006). This eventually results in a sawtooth pattern of their daily life activity level. In addition, because persisters force themselves to complete the activities they set out to do and therefore postpone rest they are hypothesized to show longer daily uptime than avoiders. The avoidance-endurance model further assumes that the most adaptive coping strategy is a combination of low avoidance and low persistence behaviour, which results in less limitations in daily life functioning (Hasenbring et al., 2001, 2006). 
The main aim of the present study is to compare characteristics of persisters and avoiders among patients with CLBP. Three hypotheses were specified:

1. Patients identified as persister or avoider will report more limitations in daily life functioning compared to patients that show low persistence and avoidance behaviour.

2. Persisters will have a higher physical activity level in daily life; will show more fluctuations in daily life activities; and will have a longer daily uptime compared to avoiders.

3. Increased activity in daily life will be associated with increased pain intensity afterwards in persisters but not in avoiders.

\section{Methods}

\subsection{Participants}

This study is part of a longitudinal cohort study in which 116 patients with CLBP participated (Huijnen et al., 2010). Inclusion criteria were: (a) low back pain: pain localized below the scapulae and above the gluteal folds for longer than 3 months (Merskey and Bogduk, 1994); (b) age between 18 and 65; (c) the low back pain is not attributable to a recognisable, known specific pathology (e.g. infection, tumour, osteoporosis, fracture, structural deformity, inflammatory disorder (e.g. ankylosing spondylitis), radicular syndrome or cauda equina syndrome) (Airaksinen et al., 2006). Exclusion criteria were (a) pregnancy; (b) serious psychiatric diseases; (c) non-fluency in Dutch. Patients were included in two different ways: 81 patients were referred by consultants in rehabilitation medicine in the southern part of the Netherlands (one rehabilitation centre, six hospital departments of rehabilitation), and 35 patients responded to an advertisement in a local newspaper. In case patients responded to the advertisement, the above mentioned selection criteria were checked by a consultant in rehabilitation medicine who performed a medical screening according to the clinical guideline for low back pain of the Dutch College of General Practitioners (Faas et al., 1996). The Medical Ethics Committee of the Maastricht University/University Hospital Maastricht, the Netherlands, approved the study protocol.

\subsection{Procedure}

Prior to participation, all subjects were informed about the purpose of the study and signed a consent form. Participants completed the self-report measures on disability, activity-related strategies, fear of movement, habitual physical activity level, pain intensity level, and depressed mood using either a paper-based or internet-based questionnaire. During a 14 day measurement period patients carried an accelerometer to measure physical activity in daily life and an electronic diary during waking hours. A short training session on using the electronic diary and the accelerometer was given. During the measurement period stand-by assistance to handle technical problems was available.

\subsection{Measures}

\subsubsection{Questionnaire assessment}

2.3.1.1. Demographic and pain-related information. Gender, age, work status and duration of complaints were recorded.. Pain intensity was measured with three $100 \mathrm{~mm}$ Visual Analogue Scales (VAS; Price et al., 1983). Patients rated their current pain and their highest and lowest pain level during the past week. A composite score was calculated from the mean of the three VASs.

2.3.1.2. Fear of movement. Fear of movement/(re)injury was assessed with the Dutch version of the Tampa Scale for Kinesiophobia
(TSK). This questionnaire contains 17 items that are rated on a 4-point scale ranging from 'strongly disagree' to 'strongly agree'. A total score can be obtained by summing all items after recoding of the reverse-keyed items. The Dutch version has been reported to be reliable and valid (Vlaeyen et al., 1995; Goubert et al., 2000).

2.3.1.3. Depressive symptoms. Depressive symptoms were assessed by the Beck Depression Inventory II (BDI-II; Gretebeck and Montoye, 1992). The BDI-II contains 21 items scored from 0 to 3. Total scores are obtained by summing the item scores resulting in total scores ranging from 0 (not depressed at all) to 63 (severely depressed). The questionnaire has good psychometric properties and is a valid questionnaire to measure the severity of depression in patients with chronic pain (Gretebeck and Montoye, 1992; Harris and D'Eon, 2008).

2.3.1.4. Disability. Low back disability was assessed using the Roland Disability Questionnaire (RDQ) (Roland and Morris, 1983a,b). This questionnaire contains 24 items measuring limitations in different activities in daily life that can be answered by yes or no. A total score is obtained by summing all items scored as "yes". The Dutch version of the RDQ has a high reproducibility and validity and is responsive to change (Gommans et al., 1997; Brouwer et al., 2004; Kuijer et al., 2005).

2.3.1.5. Habitual physical activity in daily life. To assess the level of daily life activities during the last year the Baecke Physical Activity Questionnaire (BPAQ) was used (Baecke et al., 1982). The BPAQ has 16 items that are rated on a 5-point Likert-scale. Three indices of habitual physical activity can be derived: the occupational activity index; the sport activity index and the leisure time index. The patient also reports his main occupation which is then categorized as light, moderate, or heavy work according to the level of energy expenditure. Furthermore, the two most frequently played sports are reported together with the number of hours played per week and for how many months a year. The different sports are divided into low, middle, and high level sports. The sport activity index is calculated from the intensity of the sport, the amount of time per week playing that sport, and the proportion of the year the sport was played. A total BPAQ score can be obtained by summing the means of the three indices. This total score was used in the present study. The reliability of the BPAQ in patients with LBP appears to be sufficient (Levin et al., 1999).

\subsubsection{Classification of activity-related strategies}

Patients were labelled as 'avoider' or 'persister' based on their score on the Patterns of Activity Measure-Pain (POAM-P) (Cane et al., 2007). The POAM-P is a 30 -item self-report questionnaire, developed to measure three activity patterns in patients with chronic pain, namely avoidance (10 items), overdoing (10 items) and pacing (10 items). Patients rated each item describing how they usually perform their regular daily life activities on a five point scale ranging from 0 (not at all) to 4 (always). Total scores per subscale can range from 0 to 40 . The three-factor structure of the Dutch version of the POAM-P has been confirmed (Kindermans et al., 2009). The three subscales were found to be highly internal consistent (Cronbach alphas ranging from 0.80 to 0.94 ). Significant and meaningful associations with related constructs such as fear of movement and (re)injury, pain catastrophizing, depression, and disability, confirmed the validity of the subscales (Kindermans et al., 2009). Since the focus of the current study was on an avoidant versus persistent activity-related strategy, only the results of the subscales avoidance and overdoing were used to categorize patients. The score on the pacing subscale are presented for descriptive purposes only. 
To label patients' activity-related strategies, the median score for the overdoing and avoidance subscale of the POAM-P of the patients in the present study was calculated. Patients with a score on the avoidance subscale at or above the median and a score on the overdoing subscale below the median score were defined as 'avoiders'. Patients with a score on the overdoing subscale at or above the median and below the median score on the avoidance subscale were defined as 'persisters'. In addition, patients with a score below the median on both the avoidance and the overdoing subscale were defined as 'functional performers'. Patients who scored above or at the median on both the overdoing and avoidance subscale were defined as 'mixed performers.

\subsubsection{Diary assessment}

To assess a patient's pain intensity and changes in pain intensity over time, an electronic diary was used. Furthermore, a patient's perception of his/her activity level and changes over time were registered. Diary assessment allows multiple random assessments based on the Experience Sampling Method (ESM) (Csikszentmihalyi and Larson, 1987; Huijnen et al., 2010). During a 14 day measurement period patients carried a palm-top computer (type palm $\mathrm{m} 100$ ) during waking hours. Diary questions were presented onscreen for completion via a touch screen $(50 \times 50 \mathrm{~mm})$ and entries were time- and date-stamped. Patients were informed that an alarm (beep) would randomly go off eight times a day indicating that they had to fill in a momentary assessment consisting of 43 questions. One of the questions of every momentary assessment was towards measuring a patient's current pain intensity. The level of pain intensity was assessed by means of "Right now, I am in pain". Answer categories were presented in 7-point Likert-scale ranging from 1, "not at all" to 7, "very". The question "What was my effort between this and the previous beep?" was used to assess a patient's activity level. The answer categories were: $1=$ lying down; 2 = sitting; 3 = standing; 4 = walking; 5 = cycling; 6 = sports; $7=$ sports vigorously. The maximum attainable number of completed sets of palmtop questions for the measurement period was 112. Patients were instructed to answer as many beeps as possible.

\subsubsection{Objective activity in daily life measures collected by the accelerometer}

Physical activity in daily life was assessed using a tri-axial accelerometer (RT3; Stayhealthy Inc., Monrovia, USA). Subjects were instructed to wear the RT3 during waking hours for 14 consecutive days. The accelerometer was not worn during waterbased activities (e.g. swimming, taking a shower), or in case of potential damage to the equipment (e.g. contact sports). The tri-axial accelerometer is a valid instrument for the measurement of physical activity in daily life in patients with LBP (Verbunt et al., 2001).

\subsection{Data processing}

To be included as a valid accelerometer score for physical activity in daily life, at least five valid measurement days, including one weekend day, had to be available (Gretebeck and Montoye, 1992; Huijnen et al., 2010). A valid measurement day was defined as a registration period for at least 600 consecutive minutes $(10 \mathrm{~h})$. The recorded 3-D acceleration signals were converted into one resultant acceleration signal. Next, the number of occasions (counts) per minute on which this signal exceeded a predefined threshold was stored. Data processing was performed off-line using MATLAB software (The Math Works Inc., Natick, MA). In order to be able to study the association between the objectively measured activity level and the subsequent pain intensity level, the mean activity signal between the current and previous beep of the diary were calculated. At least 25 valid diary entries had to be available in order to be used in further data analyses. Data of the first completed diary report of that day were excluded from the analysis, since answering a question concerning activities since the last beep, on that moment would include a timeframe in which patients were sleeping and not wearing the accelerometer.

\subsubsection{Daily uptime}

Because patients were instructed to wear the accelerometer the whole day during waking hours, it is possible to define the period between getting up and going to sleep. An algorithm was designed to identify this daily uptime. Firstly, a second order zero time lag low pass Butterworth filter was used to reduce signal noise. Secondly, a predefined threshold was used to identify uptime that is defined as the period between the first and last activity count that exceeded a predefined threshold $\left(U_{1}\right.$ and $U_{2}$ respectively; see Fig. 1).

\subsubsection{Mean total activity score}

The original non-filtered signal data were used to calculate the mean total activity expressed as the mean counts per day (Verbunt et al., 2005).

\subsubsection{Characteristics of the avoidance or persistence strategy}

In order to identify if a patient applies an avoidance or persistence strategy, two variables were calculated. First, an algorithm was designed in which the highest activity score within a 14-day registration (see Fig. 1) could be identified. Subsequently, in order to express the peak activity per person as a representation for persistence, the $80 \%$ power of this maximum score was then calculated and presented as $\mathrm{PA}_{\text {power. }}$ In Fig. 1, as an example the non-filtered and filtered activity signal, the highest activity peak, the $\mathrm{PA}_{\text {power }}$ of the accelerometer and pain intensity measured in the diary are shown for a restricted period of three measurement days. Second, for every patient a fluctuation score was calculated to express the level of activity fluctuations over time. To study these changes in activity over time, for 15 consecutive minutes, activity counts were summed. Next, the difference scores between a summed activity score as related to one score earlier were calculated. These difference scores can have a positive or a negative value and were therefore squared. Thereafter, a mean value was calculated. Finally, the root from this mean value was taken, to achieve a final score for the intensity of activity fluctuations in daily life over time (fluctuations act $_{\text {). }}$.

\subsection{Data analysis}

In order to study the difference in characteristics and activityrelated variables between avoiders, persisters, mixed performers and functional performers multiple one way ANOVA's were used in case of a normal distribution. In case of a significant result of the one way ANOVA, a post hoc Least Significant Difference analysis was performed to explore the difference between groups. In case of non-normal distributions of the data, the Kruskall Wallis test was used. Subsequent multiple comparisons included Mann-Whitney tests.

In order to study the association between the level of pain intensity and the objectively measured activity level over time for persisters and avoiders, a two level hierarchical linear regression analysis was performed. In multi-level modelling the repeated observations (in this model the processed activity signal of the accelerometer) are presented as Level 1 units. These observations were organized within Level 2 units, which constitute persons. A critical feature of Levels 1 and 2 observations are the independency of Level 1 and Level 2 measurements. This method anticipates on the level of variation within and between patients. In model 1, the pain intensity level was introduced as the dependent variable 


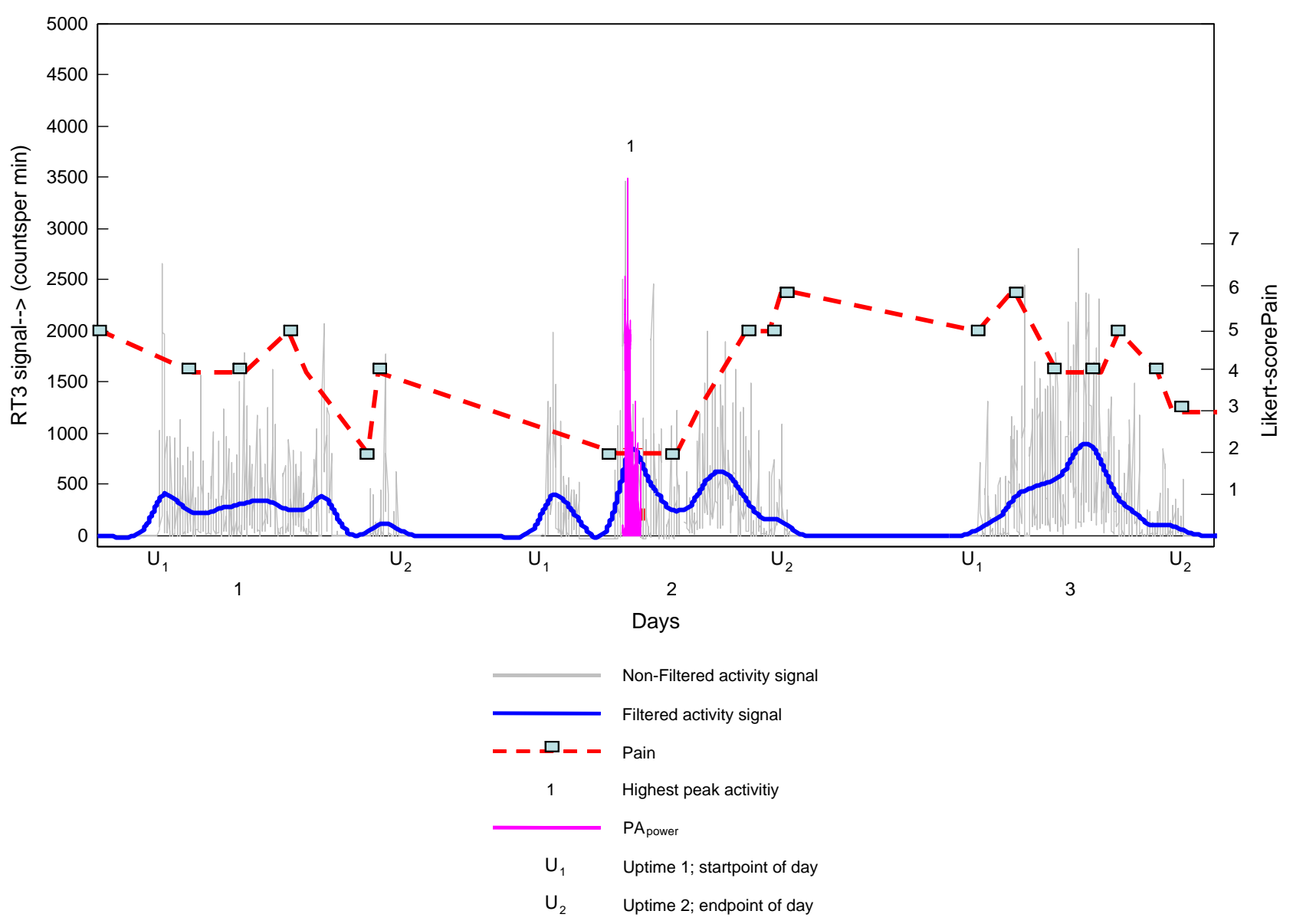

Fig. 1. An example of a registration based on the accelerometer and the diary.

in the model. In the first step, physical activity based on accelerometry and the type of activity-related strategy (avoider or persister) were introduced as independent variables. In the second step the interaction between the objective activity score and type of activity-related strategy was added. In case of a significant interaction, two additional multi-level analyses were performed, for avoiders and persisters separately. In both additional analyses, the level of pain intensity was again the dependent variable and the objectively assessed physical activity in daily life score was the independent variable. In model 2 , the procedure of model 1 was repeated, but with the independent variable being physical activity based on self-report (diary assessment) instead of physical activity based on accelerometry. In all analyses alpha was set at 0.05 . Multilevel modelling was performed using Stata 10 software (Stata Corp., 2007. College Station Texas). All other statistical analyses were performed using SPSS software version 16 (SPSS Inc., Chicago, Ill.).

\section{Results}

One hundred and seven patients participated in the accelerometer assessment. Seven patients who carried an accelerometer had an invalid activity score caused by failure of the RT3. In addition, accelerometer registrations of three patients could not be used for further analysis because the signal to noise ratio was too low. For the remaining 97 patients data were processed and the length of the daily registration of the accelerometer was evaluated. For 84 patients an accelerometer registration that fulfilled all predetermined validity criteria for activity assessment was available. Of these patients, five patients did not complete the POAM-P questionnaire, which made definition of their activity-related strategy impossible. Data of the remaining 79 patients were used in further analyses. In Fig. 2, a flow chart is shown, representing the data of patients who were used for further analysis in the current study. Demographic (gender, age, and work status) and painrelated characteristics (pain duration, level of pain intensity and disability level) of patients, whose data were not used in the analyses, were not different from patients whose data were used. Gender, duration of complaints, work status, pain intensity, and disability level did not differ significantly between patients who entered the study by consultants of rehabilitation medicine or based on inclusion by advertisement. However, patients who responded to the advertisement were significantly older (53.3 years, $\mathrm{SD}=9.0$ ) compared to patients referred by their consultant in rehabilitation medicine (age $=44.6$ years, $S D=10.3$ ).

\subsection{Description of the population}

Table 1 presents characteristics of the four subgroups based on the different activity-related strategies. Scores of patients on the avoidance and overdoing subscale were not significantly related $(r=-0.05$, ns). Avoiders, persisters and mixed performers scored significantly higher on fear of movement and depressed mood compared to functional performers. Furthermore, persisters had a lower level of fear of movement compared to avoiders and mixed performers $(p<0.01)$. The percentage of woman is higher in the group of avoiders compared to the mixed performer group $(p<0.01)$. Avoiders were found to have a higher score on the pacing subscale of the POAM-P compared to persisters and functional 


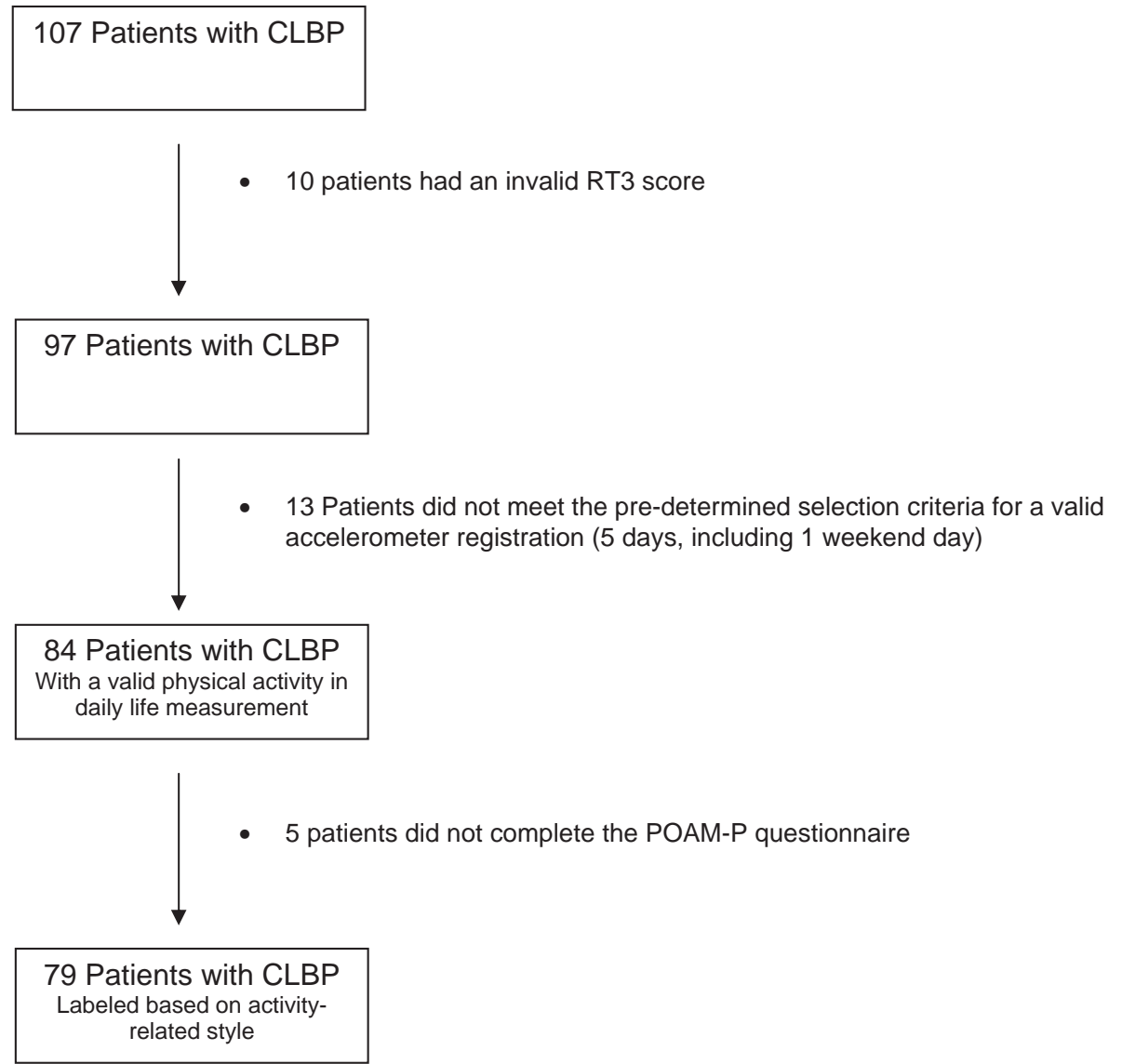

Fig. 2. Flow chart.

Table 1

Characteristics of the study population of patients with CLBP.

\begin{tabular}{|c|c|c|c|c|c|c|}
\hline & $\begin{array}{l}\text { 1. Avoiders } \\
(N=18)\end{array}$ & $\begin{array}{l}\text { 2. Persisters } \\
(N=19)\end{array}$ & $\begin{array}{l}\text { 3. Mixed performers } \\
(N=22)\end{array}$ & $\begin{array}{l}\text { 4. Functional performers } \\
(N=20)\end{array}$ & $\begin{array}{l}\text { Test } \\
\text { statistic }\end{array}$ & $\begin{array}{l}p- \\
\text { Value }\end{array}$ \\
\hline Male/female & $5 / 13^{\mathrm{a}}$ & $10 / 9^{a}$ & $17 / 5^{\mathrm{b}}$ & $11 / 9^{\mathrm{a}, \mathrm{b}}$ & $\chi^{2}=9.69$ & 0.02 \\
\hline Age & $45.7(9.8)$ & $48.2(8.4)$ & $44.2(10.9)$ & $50.6(12.5)$ & $F=1.44$ & 0.24 \\
\hline $\begin{array}{l}\text { Duration of complaints } \\
\quad \text { (months) }\end{array}$ & $83(39-261)$ & $68(32-109)$ & $116(36-219)$ & $115(40-232)$ & $\chi^{2}=2.66$ & 0.45 \\
\hline \multicolumn{7}{|l|}{ Work status (percentage) } \\
\hline -Paid job & $8(44 \%)$ & $10(53 \%)$ & $10(46 \%)$ & $12(60 \%)$ & $\chi^{2}=1.06$ & 0.79 \\
\hline -Sick leave & $2(11 \%)$ & $1(5 \%)$ & $1(5 \%)$ & 0 & $\chi^{2}=2.38$ & 0.50 \\
\hline -Disability payment & $2(11 \%)$ & $3(16 \%)$ & $6(27 \%)$ & $2(10 \%)$ & $\chi^{2}=3.15$ & 0.37 \\
\hline Fear of movement (TSK) & $41.6(6.8)^{\mathrm{a}}$ & $36.6(6.7)^{\mathrm{b}}$ & $43.9(6.6)^{a}$ & $32.1(5.5)^{\mathrm{c}}$ & $F=13.8$ & $<0.001$ \\
\hline Depressed mood (BDI-II) & $12.5(9.5-19.0)^{\mathrm{a}}$ & $12.0(8.0-17.0)^{\mathrm{a}}$ & $15.5(11.0-21.3)^{\mathrm{a}}$ & $6.5(4.0-9.8)^{\mathrm{b}}$ & $\chi^{2}=21.4$ & $<0.001$ \\
\hline Pain intensity & $48.5(15.8)^{\mathrm{a}, \mathrm{b}}$ & $50.4(17.2)^{\mathrm{a}, \mathrm{b}}$ & $55.7(17.5)^{\mathrm{a}}$ & $41.1(14.4)^{\mathrm{b}}$ & $F=2.87$ & 0.04 \\
\hline Avoidance (POAM-P) & $26.4(4.7)$ & $12.1(5.5)$ & $25.4(3.7)$ & $13.7(6.0)$ & & \\
\hline Overdoing (POAM-P) & $18.8(4.5)$ & $28.6(3.1)$ & $28.1(2.6)$ & $17.4(5.0)$ & & \\
\hline
\end{tabular}

Normally distributed data are represented by means (SD) and not normally distributed data are represented by medians (interquartile ranges).

TSK = Tampa Scale for Kinesiophobia.

BDI-II = Beck Depression Inventory II.

Avoidance $=$ Score on the avoidance subscale of the POAM-P.

Overdoing $=$ Score on the overdoing subscale of the POAM-P.

$\mathrm{a}, \mathrm{b}, \mathrm{c}$ Values with the same superscripts represent homogenous subsets.

performers $(p<0.01)$. Furthermore, mixed performers scored also higher on pacing than persisters $(p<0.05)$.

\subsection{Disability, daily uptime, and physical activity in daily life}

Table 2 presents the scores on activity-related variables for the four subgroups. Both avoiders and mixed performers felt significantly more disabled as compared to persisters and functional performers. Persisters had a significantly higher disability level compared to functional performers $(p<0.05)$. Furthermore, avoiders reported to be less active on the BPAQ compared to persisters and functional performers $(p<0.05)$. Mean daily uptime of persisters was $889 \mathrm{~min}(\mathrm{SD}=65.0)$, which is significantly higher than the uptime for avoiders $(820 \mathrm{~min} \quad(\mathrm{SD}=66.2)$, $p<0.01$ ). The objectively assessed activity level, the level of activity fluctuations over time, and the power of the highest activity peak did not differ significantly between avoiders and persisters. 
Table 2

Scores on activity-related variables for the different activity-related behavior styles.

\begin{tabular}{|c|c|c|c|c|c|c|}
\hline & $\begin{array}{l}\text { 1. Avoiders } \\
(N=18)\end{array}$ & $\begin{array}{l}\text { 2. Persisters } \\
(N=19)\end{array}$ & $\begin{array}{l}\text { 3. Mixed performers } \\
(N=22)\end{array}$ & $\begin{array}{l}\text { 4. Functional performers } \\
(N=20)\end{array}$ & $\begin{array}{l}\text { Test } \\
\text { statistic }\end{array}$ & $\begin{array}{l}p- \\
\text { Value }\end{array}$ \\
\hline Disability (RDQ) & $13.6(3.6)^{\mathrm{a}}$ & $10.8(3.6)^{\mathrm{b}}$ & $13.9(4.1)^{\mathrm{a}}$ & $8.0(3.5)^{\mathrm{c}}$ & $F=11.1$ & $<0.001$ \\
\hline Habitual activity level (BPAQ) & $7.8(6.9-8.9)^{\mathrm{a}}$ & $9.2(7.4-10.6)^{\mathrm{b}, \mathrm{c}}$ & $8.3(7.5-9.5)^{\mathrm{a}, \mathrm{b}}$ & $9.0(8.3-10.2)^{\mathrm{c}}$ & $\chi^{2}=8.95$ & 0.03 \\
\hline Uptime (in min) & $820(66.2)^{a}$ & $889(65.0)^{\mathrm{b}}$ & $866(75.5)^{a, b}$ & $854(87.0)^{a, b}$ & $F=2.76$ & 0.05 \\
\hline $\begin{array}{l}\text { Objective Activity (in } \\
\text { counts } \times 10^{3} \text { ) }\end{array}$ & $187(133-276)$ & $214(178-247)$ & $196(155-296)$ & $178(138-219)$ & $\chi^{2}=2.32$ & 0.51 \\
\hline Fluctuations $_{\text {act }}$ & $310(251-424)$ & $326(273-491)$ & 337 (266-439) & $350(283-504)$ & $\chi^{2}=0.63$ & 0.88 \\
\hline $\mathrm{PA}_{\text {power }}\left(\right.$ in counts $\times 10^{3}$ ) & $52.6(39.8-72.8)$ & $46.8(33.2-74.6)$ & $43.1(35.9-90.6)$ & $47.6(33.7-70.3)$ & $\chi^{2}=0.70$ & 0.87 \\
\hline
\end{tabular}

Normally distributed data are represented by means (SD) and not normally distributed data are represented by medians (interquartile ranges).

RDQ = Roland Disability Questionnaire.

$\mathrm{BPAQ}=$ Baecke Physical Activity Questionnaire

a,b,c Values with the same superscripts represent homogenous subsets.

Table 3

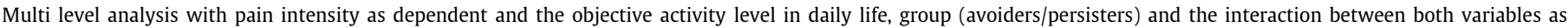
independent variables.

\begin{tabular}{|c|c|c|c|c|c|}
\hline & Main effects & $\beta$ & SE & $Z$ & $P$ \\
\hline \multicolumn{6}{|c|}{$\begin{array}{l}\text { Wald }=1.65, p=0.44 \\
\text { Step } 1\end{array}$} \\
\hline Pain intensity & $\begin{array}{l}\text { Objective activity level } \\
\text { Group (avoiders/persisters) }\end{array}$ & $\begin{array}{l}0.02 \\
-0.08\end{array}$ & $\begin{array}{l}0.02 \\
0.28\end{array}$ & $\begin{array}{l}1.25 \\
-0.30\end{array}$ & $\begin{array}{l}0.21 \\
0.77\end{array}$ \\
\hline \multicolumn{6}{|c|}{$\begin{array}{l}\text { Wald }=1.66, p=0.65 \\
\text { Step } 2\end{array}$} \\
\hline Pain intensity & Group $\times$ objective activity & 0.00 & 0.04 & 0.06 & 0.96 \\
\hline
\end{tabular}

\subsection{The association between pain intensity level and activity}

Table 3 presents the results of the multilevel analyses of model 1 with the level of pain intensity as dependent and the objectively assessed activity level, the group variable avoiders/persisters and the interaction between both variables as independent variables. Note that these analyses only included the data of patients that fulfilled the pre-determined validity criteria for diary assessment. Eventually a valid diary assessment was available for 30 of the 37 patients classified as avoider $(N=14)$ and persister $(N=16)$. No significant model, associations or interaction were found. Table 4 shows the results of model 2 including the self-reported activity level based on the diary as independent variable instead of the objectively assessed physical activity level in model 1 . In the first step, a significant model was found in which a higher self-reported physical activity level between two beeps was related to a higher level of pain intensity at the moment of the last beep ( $\beta=0.09, p<0.001$, Wald $\chi^{2}=24.99, p<0.001$ ). In the second step, the interaction term was added which contributed significantly to the model $(\beta=0.15, p<0.001)$. The analysis per subgroup (Table 5 ) revealed that the association between the pain intensity level and self-reported activity level in avoiders was not significant. In contrast, in persisters the level of physical activity assessed in the diary significantly explained the level of pain intensity $\left(\beta=0.15, p<0.001\right.$, Wald $\left.\chi^{2}=40.95, p<0.001\right)$.

\section{Discussion}

This study aimed to compare characteristics of patients with CLBP based on different activity-related strategies. Furthermore, associations between pain intensity level and self-reported and objectively assessed daily life activity level were evaluated within patients classified as avoiders and persisters on the basis of their POAM-P score.

This study could not confirm a lower mean objectively assessed activity level for avoiders compared to persisters. One might speculate that patients classified as avoiders are especially prone to avoid specific activities or postures that they fear might cause a pain increase. If they do perform other non-feared activities their mean activity level may still be comparable to patients classified as persisters. The accelerometer is not able to register enough details to differentiate between various types of activities (such as standing, walking, and cycling). Although accelerometry provides a valid representation of global activities in daily life (Verbunt et al., 2001), no information is obtained about specific postures and type of activities. For future research, it is recommended to use an activity monitor, which enables the identification of different types of activities and postures (Bussmann et al., 2001; van den BergEmons et al., 2007). It can than be established whether specific types of activities are avoided.

In contrast to objectively assessed mean activity level, self-reported activity level, measured with the BPAQ, was lower in avoiders compared to persisters. Avoiders also reported a higher level of fear of movement, which is in line with the fear-avoidance model (Vlaeyen and Linton, 2000). Our finding that avoiders have a shorter period of daily uptime compared to persisters is consistent with earlier research that showed that higher levels of pain-related fear were associated with longer periods of bed rest in patients with acute low back pain (Verbunt et al., 2008). This suggests that in avoiders, pain-related fear forces a patient to have a shorter daily uptime, whereas in persisters the drive to finish all activities eventually results in a longer daily uptime. Furthermore, previous research also found that the subjectively reported standing and walking time were lower in patients classified as avoiders than in patients with a behavioural pattern that resembles our persister group (McCracken and Samuel, 2007). However, no reference values for daily uptime in healthy individuals are available. Future research on this theme seems recommendable.

Another intriguing finding is that in persisters a higher activity level as reported in the diary, seems to result in an increase of pain, whereas in avoiders no association between pain and activity could be found. This could imply that, during activities, persisters indeed 
Table 4

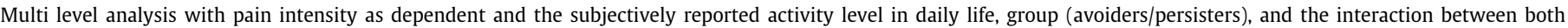
variables as independent variables.

\begin{tabular}{|c|c|c|c|c|c|}
\hline & Main effects & $\beta$ & SE & $Z$ & $P$ \\
\hline \multicolumn{6}{|c|}{$\begin{array}{l}\text { Wald }=24.99, p<0.001 \\
\text { Step } 1\end{array}$} \\
\hline Pain intensity & $\begin{array}{l}\text { Subjective activity level } \\
\text { Group (avoiders/persisters) }\end{array}$ & $\begin{array}{l}0.09 \\
-0.10\end{array}$ & $\begin{array}{l}0.02 \\
0.29\end{array}$ & $\begin{array}{l}4.99 \\
-0.36\end{array}$ & $\begin{array}{l}<0.001 \\
0.72\end{array}$ \\
\hline \multicolumn{6}{|c|}{$\begin{array}{l}\text { Wald }=42.57, p<0.001 \\
\text { Step } 2\end{array}$} \\
\hline Pain intensity & Group $\times$ subjective activity & 0.15 & 0.04 & 4.17 & $<0.001$ \\
\hline
\end{tabular}

Table 5

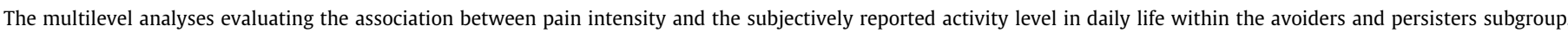

\begin{tabular}{|c|c|c|c|c|c|}
\hline & Main effects & $\beta$ & SE & $Z$ & $P$ \\
\hline $\begin{array}{l}\text { Wald }=0.01, p \\
\text { Avoiders }\end{array}$ & & & & & \\
\hline Pain intensity & Subjective activity level & 0.00 & 0.03 & -0.12 & 0.91 \\
\hline $\begin{array}{l}\text { Wald }=40.95, p \\
\text { Persisters }\end{array}$ & & & & & \\
\hline Pain intensity & Subjective activity level & 0.15 & 0.02 & 6.40 & $<0.001$ \\
\hline
\end{tabular}

ignore their pain and try to finish the activity which results in a higher level of pain afterwards. The novelty of the current study is that the association between pain and activity within daily life activities were evaluated for persisters and avoiders separately. Other studies evaluating this relationship in patients with pain did not differentiate between differences in activity-related strategies of the individual patients. They indeed reported an association between activity and pain in acute pain, but not in the chronic phase (Vendrig and Lousberg, 1997; Liszka-Hackzell and Martin, 2004). In the current study there was no association between the objectively assessed activity level and current pain intensity level, but in patients classified as persister an association was found between self-reported activity level and the level of pain intensity. A possible reason for this discrepancy could be that the perception of persisters of their actual daily life activities is distorted (Huijnen et al., 2010). When peristers notice an increase in their pain they might infer that this is caused by having been more active in the preceding time period. Another reason for the difference in findings between the objective and diary assessment could again be that the accelerometer cannot differentiate between different activities. For patients with CLBP some activities or postures can cause a pain increase, whereas other activities with similar acceleration signals have no influence on pain intensity.

Both avoiders and persisters felt more disabled in their daily life functioning than functional performers. Furthermore, avoiders reported more limitations in their functioning compared to persisters. This finding could also be based on the fact that the current available disability questionnaires especially focus on avoidancerelated disability instead of persistence-related disability. Some items in the RDQ (e.g., "I avoid heavy jobs around the house because of my back.", "I sit down for most of the day because of my back", and "Because of my back, I lie down to rest more often.") will not be positively confirmed by persisters, whereas avoiders will. Although persisters will probably continue with the performance of activities, they can perceive themselves as disabled in performing physical and/or social activities. Therefore, more research is needed to solve the issue whether persisters indeed perceive less limitations or that measuring disability in persisters is more complicated and that the validity of existing questionnaires is limited for this specific patient group.

An unexpected finding was the high number of patients in the mixed performer group. Initially, persistence and avoidance were assumed to be two opposite strategies on a continuum, as proposed in the avoidance-endurance model (Hasenbring et al., 2001, 2006). However, a substantial number of patients scored high on both persistence and avoidance behaviour. This mixed performer group showed higher levels of fear of movement, pain intensity, depression, disability, and a lower self-reported activity level compared to the functional performers. In this mixed performer group, it might be that it is context-dependent whether a patient persists or avoids activities. Patients in this mixed performer group seem to be at least as dysfunctional as persisters and avoiders. The characteristics of this mixed performer group shows similarities with the characteristics of the 'extreme cycler' as identified by McCracken and Samuel (2007). The extreme cyclers were characterized by high levels of confronting (resembling persistence), avoidance, and pacing. This group reported more pain, anxiety and physical disability than the medium cycler group (comparable to the functional group in this study). Future studies should gain more insights in a patients' decision for using either avoidance or persistence strategies in their daily life activities.

One limitation of the current study is the limited number of patients in each group. Eventually, the data of 23 patients could not be used for further analyses. Of these 23 patients, 10 had an invalid RT3 score and data of 13 patients did not meet the predefined data selection criteria for valid physical activity assessment. In addition, seven patients classified as avoider or persister did not have a diary assessment and therefore data of these patients could not be used in the analyses evaluating the association between pain intensity (derived from the diary) and objectively assessed level of physical activity (with accelerometry). For future research it is recommended to further develop the measurement techniques to prevent drop-outs due to failure of the accelerometer or electronic diary.

This study has clinical implications. Current cognitive-behavioural treatment approaches of CLBP are predominantly aimed at restoring physical functioning in patients showing avoidance behaviour. Exposure in vivo and graded activity are evidencebased interventions that appear to be highly effective in reducing disability in this subgroup of patients (Leeuw et al., 2008).This study demonstrates that not only activity avoidance but also persistence is associated with increased disability. The optimal treatment approach for patients employing a persistent strategy might however be different from that which is being used for patients 
with an avoidant strategy. A recent study applied tailored treatments for fibromyalgia patients showing either avoidance or persistence behaviour and found that these led to significant improvements in physical and psychological functioning (van Koulil et al., 2010). A similar approach might be useful for patients with CLBP showing distinct activity-related behaviour patterns. Developing tailored treatments for all subgroups of patients with CLBP is a future challenge.

\section{Acknowledgements}

This study was supported by the Council for Medical and Health Research of the Netherlands (ZON-MW), Grant No. 14350042. Participation of Dr. Roelofs was supported by the EFIC-Grünenthal-Grant (EGG). The authors have no conflicts of interest relevant to this work.

\section{References}

Airaksinen O, Brox JI, Cedraschi C, Hildebrandt J, Klaber-Moffett J, Kovacs F, et al. Chapter 4. European guidelines for the management of chronic nonspecific low back pain. Eur Spine J 2006;15(Suppl. 2):S192-300.

Baecke JA, Burema J, Frijters JE. A short questionnaire for the measurement of habitual physical activity in epidemiological studies. Am J Clin Nutr 1982;36(5):936-42.

Birkholtz M, Aylwin M, Harman RM. Activity pacing in chronic pain management: one aim, but which method? Part one: introduction and literature review. $\mathrm{Br} J$ Occup Ther 2006;67(10):447-52.

Bousema EJ, Verbunt JA, Seelen HA, Vlaeyen JW, Knottnerus JA. Disuse and physical deconditioning in the first year after the onset of back pain. Pain 2007;130(3):279-86.

Brouwer S, Kuijer W, Dijkstra PU, Goeken LN, Groothoff JW, Geertzen JH. Reliability and stability of the Roland Morris disability questionnaire: intra class correlation and limits of agreement. Disabil Rehabil 2004;26(3):162-5.

Bussmann JB, Martens WL, Tulen JH, Schasfoort FC, van den Berg-Emons HJ, Stam $\mathrm{HJ}$. Measuring daily behavior using ambulatory accelerometry: the activity monitor. Behav Res Methods Instrum Comput 2001;33(3):349-56.

Cane D, Nielson WR, McCarthy M, Mazmanian D. Development and preliminary evaluation of a measure of three pain-related patterns of activity. In: 27 th annual canadian pain society meeting. Ottawa, Ontario; 2007.

Csikszentmihalyi M, Larson R. Validity and reliability of the experience-sampling method. J Nerv Ment Dis 1987;175(9):526-36.

Faas A, Chavannes AW, Koes BW, van den Hoogen JMM, Mens JMA, Smeele LJM, et al. Practice guideline "Low Back Pain" [Translation]. Utrecht; 1996

Gommans JHB, Koes BW, van Tulder MW. Validiteit en responsiviteit Nederlandstalige Roland Disability Questionnaire. Vragenlijst naar functionele status bij patienten met lage rugpijn. Ned Tijdschr Fysiother 1997;107(2): 28-33.

Goubert L, Crombez G, Vlaeyen J, Van Damme S, Van Den Broeck A, Van Houdenhove B. De Tampa Schaal voor Kinesiofobie: Psychometrische karakteristieken en normering (The Tampa scale Kinesiophobia: psychometric properties and norms). Gedrag Gezond 2000;28:54-62.

Gretebeck RJ, Montoye HJ. Variability of some objective measures of physical activity. Med Sci Sports Exerc 1992;24(10):1167-72.

Harding V, Williams A. Activities training: integrating behavioral and cognitive methods with physiotherapy in pain management. J Occup Rehabil 1998;8(1): 47-60.

Harris CA, D'Eon JL. Psychometric properties of the beck depression inventory second edition (BDI-II) in individuals with chronic pain. Pain 2008;137(3): $609-22$.
Hasenbring M, Hallner D, Klasen B. Psychological mechanisms in the transition from acute to chronic pain: over- or underrated? Schmerz 2001:15(6):442-7.

Hasenbring MI, Plaas H, Fischbein B, Willburger R. The relationship between activity and pain in patients 6 months after lumbar disc surgery: do pain-related coping modes act as moderator variables? Eur J Pain 2006;10(8):701-9.

Hasenbring MI, Verbunt JA. Fear-avoidance and endurance-related responses to pain: new models of behavior and their consequences for clinical practice. Clin J Pain 2010;26(9):747-53.

Huijnen IP, Verbunt JA, Peters ML, Delespaul P, Kindermans HP, Roelofs J, et al. Do depression and pain intensity interfere with physical activity in daily life in patients with chronic low back pain? Pain 2010;150(1):161-6.

Kindermans H, Roelofs J, Goossens M, Huijnen I, Verbunt J, Vlaeyen J. Measuring avoidance, overdoing and pacing in patients with chronic pain: psychometric properties of the patterns of activity measure-pain. Eur J Pain 2009;13(Suppl. 1):S222-3.

Kuijer W, Brouwer S, Dijkstra PU, Jorritsma W, Groothoff JW, Geertzen JH. Responsiveness of the Roland-Morris disability questionnaire: consequences of using different external criteria. Clin Rehabil 2005;19(5):488-95.

Leeuw M, Goossens ME, Linton SJ, Crombez G, Boersma K, Vlaeyen JW. The fearavoidance model of musculoskeletal pain: current state of scientific evidence. J Behav Med 2007;30(1):77-94.

Leeuw M, Goossens ME, van Breukelen GJ, de Jong JR, Heuts PH, Smeets RJ, et al. Exposure in vivo versus operant graded activity in chronic low back pain patients: results of a randomized controlled trial. Pain 2008;138(1):192-207.

Levin S, Jacobs Jr DR, Ainsworth BE, Richardson MT, Leon AS. Intra-individual variation and estimates of usual physical activity. Ann Epidemiol 1999;9(8): 481-8.

Liszka-Hackzell JJ, Martin DP. An analysis of the relationship between activity and pain in chronic and acute low back pain. Anesth Analg 2004:99(2):477-81.

McCracken LM, Samuel VM. The role of avoidance, pacing, and other activity patterns in chronic pain. Pain 2007;130(1-2):119-25.

Merskey H, Bogduk N. Classification of chronic pain. Seattle: IASP Press; 1994.

Price DD, McGrath PA, Rafii A, Buckingham B. The validation of visual analogue scales as ratio scale measures for chronic and experimental pain. Pain $1983 ; 17(1): 45-56$

Roland M, Morris R. A study of the natural history of back pain. Part I: development of a reliable and sensitive measure of disability in low-back pain. Spine 1983a;8(2):141-4.

Roland M, Morris R. A study of the natural history of low-back pain. Part II: development of guidelines for trials of treatment in primary care. Spine 1983b;8(2):145-50.

van den Berg-Emons RJ, Schasfoort FC, de Vos LA, Bussmann JB, Stam HJ. Impact of chronic pain on everyday physical activity. Eur J Pain 2007;11(5):587-93.

van Koulil S, van Lankveld W, Kraaimaat FW, van Helmond T, Vedder A, van Hoorn $\mathrm{H}$, et al. Tailored cognitive-behavioral therapy and exercise training for highrisk patients with fibromyalgia. Arthritis Care Res (Hoboken) 2010;62(10): 1377-85.

van Weering MG, Vollenbroek-Hutten MM, Tonis TM, Hermens HJ. Daily physical activities in chronic lower back pain patients assessed with accelerometry. Eur J Pain 2009;13(6):649-54.

Vendrig AA, Lousberg R. Within-person relationships among pain intensity, mood and physical activity in chronic pain: a naturalistic approach. Pain 1997;73(1):71-6.

Verbunt JA, Sieben J, Vlaeyen JW, Portegijs P, Andre Knottnerus J. A new episode of low back pain: who relies on bed rest? Eur J Pain 2008;12(4):508-16.

Verbunt JA, Sieben JM, Seelen HA, Vlaeyen JW, Bousema EJ, van der Heijden GJ, et al. Decline in physical activity, disability and pain-related fear in sub-acute low back pain. Eur J Pain 2005;9(4):417-25.

Verbunt JA, Westerterp KR, van der Heijden GJ, Seelen HA, Vlaeyen JW, Knottnerus JA. Physical activity in daily life in patients with chronic low back pain. Arch Phys Med Rehabil 2001;82(6):726-30.

Vlaeyen JW, Kole-Snijders AM, Boeren RG, van Eek H. Fear of movement/(re)injury in chronic low back pain and its relation to behavioral performance. Pain 1995;62(3):363-72.

Vlaeyen JW, Linton SJ. Fear-avoidance and its consequences in chronic musculoskeletal pain: a state of the art. Pain 2000;85(3):317-32. 